\title{
Gaziantep Kent Konutunda Mekân Kurgusu Değişiminin 1960-1980 Dönemi Örneklerinde İzlenmesi
}

\author{
Monitoring the Changes of Spatial Configuration of Gaziantep Urban Housing \\ Through The Samples of 1960-1980 Period
}

\author{
Onur Erman* ${ }^{*}$, Esra Kasapbaşı* ${ }^{* *}$
}

\section{Öz}

Erken Cumhuriyet dönemiyle başlayan yenileşme ve modernleşme hareketinin etkilerinin 1950'li yıllardan itibaren, Gaziantep kentinde görüldüğü söylenebilir. Bu yıllardan itibaren modern yaşamın konut mekânına da yansıdığı, geleneksel konut yapısının yerini yenilikçi anlayışla tasarlanan konutlara bıraktığı görülür. Bu kapsamda çalışma; konutun toplumsal yaşamın yansıması olduğu, toplumun değişen dinamiklerinin konut mekânının biçimlenişini etkilediği varsayımına dayanarak konut mekânının değişimi üzerine odaklanmaktadır. Bu çerçevede Gaziantep 1960-1980 dönemi kent konutları onar yıllık dönemler içinde ele alınarak konut mekân kurgusunun değişimi analiz edilmiştir. Böylelikle 1960-1980 yılları arasında Gaziantep kenti özelinde görülen sosyo-kültürel ve sosyo-ekonomik değişimlerin konut kültürüne yansımasının ve konutun biçimlenişine etkisinin tespit edilmesi hedeflenmiştir. Ayrıca konutun biçimlenişinde geleneksel ve modern yaşama ait unsurların, plan özelliklerine ve mekân kurgusuna etkisi saptanmak istenmiştir. Konut mekân kurgusundaki değişimlerin belirlenmesi amacıyla mekân dizilimi (space syntax) analiz teknikleri kullanılmıştır. Ulaşılan sonuçlar; geleneksel yaşama ait ögelerin konut şemasının biçimlenişini etkilediğini, konut mekân kurgusunun dönemler içinde değiştiğini, değişimde sosyal ve kültürel faktörlerin etkisini işaret etmektedir.

\section{Anahtar Kelimeler}

Konut, Konut Kültürü, Mekân Kurgusu, Mekân Dizilimi Analizi, Gaziantep

\section{Abstract}

The effects of the modernization movement, which initiated with the Early Republican Period, began to be monitor in Gaziantep city in the 1950s. In this period, the modern life started to be reflected in the housing space, and the traditional houses were being replaced with the houses which were designed with a modernist approach. In this context, the study focuses on the changes of the housing space, based on the assumptions that housing is the reflection of social life and the changing dynamics of the society affects the formation of the housing space. The changes of spatial configuration of the Gaziantep urban houses constructed between the years 1960 to 1980 were analyzed to determine the effects of socio-cultural and socio-economic changes on the housing culture and the housing formation. It was also aimed to determine how the traditional and modern elements of lifestyle effect the plan features and spatial configuration of the residential space. Space syntax analysis techniques were used to analyze and determine the changes in residential space configuration. The achieved results pointed out that traditional elements effect the formation of the modern housing

* Sorumlu Yazar: Onur Erman (Doç. Dr.), Çukurova Üniversitesi, Mimarlık Fakültesi, Mimarlık Bölümü, Adana, Türkiye. E-posta: oerman@cu.edu.tr ORCID: 0000-0002-4732-5975

** Esra Kasapbaşı (Doktora Öğrencisi), Çukurova Üniversitesi, Fen Bilimleri Enstitüsü, Mimarlık Anabilim Dalı, Adana, Türkiye. E-posta: esra_kasapbasi@hotmail.com ORCID: 0000-0002-7012-336X

Attf: Erman, Onur ve Kasapbasi, Esra. “Gaziantep Kent Konutunda Mekân Kurgusu Değişiminin 1960-1980 Dönemi Örneklerinde İzlenmesi." Art-Sanat, 14(2020): 135-157. https://doi.org/10.26650/artsanat.2020.14.0006 
scheme, the configuration of the housing space has changed over time, and social and cultural factors have an impact on the change.

\section{Keywords}

Housing, Housing Culture, Spatial Configuration, Space Syntax Analysis, Gaziantep

\section{Extended Summary}

Culture is a whole and consists of the values that shape human life. As abstract concepts, cultural values are embodied in various forms, like a functional space, a tool, or a behavior pattern when they are involved in human life. In addition to cultural values, the lives of individuals are shaped by the political, economic and social conditions of the society in which they belong. With the change of these conditions, the spaces in which life passes are reshaped. In this process, changing lifestyles inevitably define new forms of behavior and create new spatial needs. As a natural consequence of this situation, new uses and spatial relations are expected to emerge.

The relationship between society and space is a reciprocal and dynamic phenomenon. Lefebvre states that space is a product of society and that social, economic and political elements, which are unique to society, shape the physical environment. According to him, shaping is a mutual process, and the space produced by society becomes a means of reproducing itself. This statement explains how spaces and spatial fictions are formed that are distinctive for the society.

The proclamation of the Republic in our country and the process of restructuring and development in every field after that has brought changes in the lives of the society and individuals. Studies on the spatial formation of the Republican era residence based on social and cultural change began to emerge in the early 2000s. Güney examined the spatial reflections of the new life that came with the Republic through period apartments in Ankara, while Erman et al. questioned the impact of social, cultural and economic changes on the shaping of the housing space via the research completed in 2007. In addition to similar studies, Dursun analyzed the dwellings that were built in different periods and belonged to different cultural groups within the urban fabric of Trabzon. The common results of these studies can be summarized as the space is shaped by the character of the period, each period creates its own space, cultural tendencies and cultural behaviors are embodied within space and spatial relations, and although similarities are observed in the use of space in different cultures, differences occur in spatial relations.

It can be said that the effects of the modernization movement that started with the Early Republican era begun to be seen in Gaziantep city in the 1950s. Since these years, it is seen that modern life has started to come into being in the housing space and the traditional housing structure has been replaced by the houses designed with 
a modernist approach. Before the Republican era, traditional Antep Houses, which consisted of rooms facing the same courtyard or sofa, were the common residential buildings where crowded families resided in the city. Each of the rooms was a separate residence in itself and several generations lived in the same dwelling in a patriarchal family order. The changing socio-cultural and socio-economic structure inevitably affected the existing family life. The increase in the level of education of family members and the fact that women are more involved in business and social life together with men have enabled the outward way of life to become widespread. The individuals, who started to live their lives as required by modernization, turned to the renewal of the place where they lived. As a result of this, modern houses were built in this period in such a way that the elders of the family and each of the married children could live on a separate floor. It is possible to say that this situation is an indicator of the effort to maintain the family integrity in the modern housing life. Therefore, it is thought that the change in social and cultural structure is reflected in Gaziantep's housing culture and the modernist attitude of the period has caused the change of housing schemes. This new architecture has also changed the shape and spatial relations of the residential space.

In this context, the aim of this study is to determine the change of the configuration of the house based on the assumption that the housing is a reflection of the social life and the changing dynamics of the society affect the shaping of the housing space. In order to determine the effect of socio-cultural and socioeconomic changes on housing culture and housing, ten housing schemes that were built between 1960 and 1980 were analyzed. In addition, it was aimed to determine the effect of traditional and modern elements on the plan features and spatial structure in the shaping of the house. Space syntax analysis technique was used to observe the change.

Space syntax analysis method was developed by Bill Hillier and his team at the University College of London (UCL) in the early 1970s. The aim of the method is to reveal the interactions of the spatial relations in a built environment with the social environment. In this study, space syntax analysis was performed by using the Depthmap X package program developed by Alasdair Turner and Eva Friedrich in UCL Space Syntax Laboratory between 2000-2011. Within the scope of the study, Step Depth Analysis and Justified Graph Analysis were performed by using space syntax method. In the frame of the analysis, residential spaces were grouped according to their functional features and user's characteristics. Accordingly, spatial groups were as follows:
a) Non-residential user spaces
b) Residential user spaces
c) Service locations
d) Halls and connection areas 
The results of the study pointed out that traditional elements affect the formation of the housing plan, the configuration of the housing area changes over time and the impact of social and cultural factors on change. Although it was in the same geography, it was clearly seen that the changing of the life style and the differentiation in living culture conditions over time caused the housing scheme to change. This result confirmed once more that housing is a cultural element and it is a reflection of life. 


\section{Giriș}

Yaşadığımız çevrenin bileşeni ve bir anlamda fiziksel çevrenin yapıtaşı olan mekân, insanın ve onun yaşamının ürünü olarak biçimlenir. İnsan yaşamını sadece fiziki olarak görülen somut olguların bir bütünü olarak düşünmek sınırlı bir bakış açısı getirecektir. Yaşama dâhil olan ve hatta yaşamı kurallı hâle getiren, soyut kavramlarla insanın ideasında yer alan, ancak yaşantıya aktarıldığında somut olarak gözlenebilen unsurlar, yaşamı ve doğal olarak yaşanan mekânı biçimlendirir. Bu bakımdan kültürün fiziksel çevrenin biçimlenmesindeki etkisini vurgulamak gerekir. Bireylerin yaşamlarını kültürel değerlerin yanı sıra, ait olunan toplumun içinde bulunduğu dönemin siyasi, ekonomik ve sosyal koşulları biçimlendirirken, bu koşulların değişimiyle yaşamın geçtiği mekânlar yeniden şekillenir. Bu süreç içinde değişen yaşam biçimleri kaçınılmaz olarak yeni davranış biçimlerini tanımlar ve yeni mekânsal ihtiyaçları doğurur. Bu durumun doğal sonucu olarak yeni kullanımların ve mekânsal ilişkilerin ortaya çıkması beklenir.

Lefebvre, Mekânın Üretimi isimli çalışmasında mekân ve toplum ilişkisini ele alarak, mekânın, toplumun bir ürünü olduğunu, topluma has sosyal, ekonomik ve politik unsurların fiziksel çevreyi biçimlendirdiğini belirtir ${ }^{11}$. Ancak ona göre biçimlendirme, karş1lklı bir süreçtir ve toplumun ürettiği mekân, toplumun kendisini tekrar üretmesinde bir araç olur. Lefebvre bu yaklaşımıyla, toplum-mekân ilişkisine bir bakış açısı getirirken, toplumlara özgü mekânların ve mekânsal kurguların nasıl oluştuğunu açıklamaktadır. Lefebvre'ye göre toplumun mekânsal pratiklerinin (toplumun) kendi mekânını yaratmasıyla, topluma özgü mekânsal pratikleri ve yaşam alışkanlıklarını içeren ve biçimlendiren algılanan mekân oluşur ${ }^{22}$. Mekânsal pratiklerin somutlaştığ algılanan mekân aynı zamanda onu kullananların ve yaşayanların temsil mekânlarıdır. Mekân, temsil mekânı olarak imgeler ve semboller dünyasıyla ilişkilidir. İmgeler ve semboller aracılığıyla kullanıcısını temsil eder ve onun dış dünyayla ilişkisini kurar.

Vidler de mekân kullanımının insan aktiviteleriyle oluştuğunu, boşluğun insanların karşılıklı ilişkileriyle mekânsal ve işlevsel olarak tanımlandığını belirtir. Mekân kurgusunu şekillendiren ilişkiler; insan ilişkilerinin, dolayısıyla daha büyük ölçekte, insan ilişkilerini belirleyen toplumsal olayların etkisiyle oluşur. Bu bakımdan mekân, sosyal süreçlerin de önemli bir göstergesidir ${ }^{3}$.

Mekân ve toplum ilişkisinin bu denli iç içe geçmiş olması dolayısıyla toplumsal yapıda görülen değişimlerin konut mekânını etkilemesi ve değiştirmesi kaçınılmazdır. Konut bireysel yansımaların ötesinde, toplumsal yaşam alışkanlıkları gibi paylaşılan değerlerin de dâhil olduğu yaşam kültürünün somutlaştığı, fiziksel olarak temsil

1 Henry Lefebvre, Mekânın Üretimi, çev. Iş̧1k Ergüden (İstanbul: Sel Yayınc1lık, 2014), 56-94.

2 Lefebvre, Mekânın Üretimi, 67.

3 Anthony Vidler, Warped Space (Cambridge: The MIT Press, 2000), 68. 
edildiği alandır. Bu bakımdan toplumların değişimi ve gelişiminden konut mekânı da etkilenerek biçim ve yapı değiştirir. Bu bağlamda, bireyin yaşamını etkileyen her değişimin, dolayısıyla toplumsal ölçekte etkisi ortaya çıkan değişimlerin, konutun biçimlenişine yansıması kaçınılmazdır.

Ülkemizde Cumhuriyet'in ilanı ve sonrasında yaşanan her alanda yeniden yapılanma ve gelişme süreci, toplumun ve bireylerin yaşantısında da değişimleri beraberinde getirmiştir. Cumhuriyet dönemi konutunun mekânsal biçimlenişini sosyal ve kültürel değişime dayandırarak inceleyen çalışmalar 2000'lerin ilk yıllarında belirmeye başlamıştır. Cumhuriyet'le gelen yeni yaşamın mekânsal yansımalarını Güney, Ankara'da dönemin apartman yapıları üzerinden incelerken, Erman vd. 2007 yılında tamamlanan araştırmayla sosyal, kültürel ve ekonomik değişimlerin konut mekânının biçimlenişine etkisini sorgulamıştır ${ }^{4}$. Benzer çalışmaların yanında Dursun, 2002 yılında tamamladığ çalışmasında, Trabzon kent dokusu içinde farklı dönemlerde inşa edilmiş ve fark11 kültür gruplarına ait olan konutları analiz etmiştir ${ }^{5}$. Konu alanında yapılmış olan çalışmalar genel olarak değerlendirildiğinde; değişimin yurt genelinde yayılmakla birlikte her ilde farklı hızlarda ve süreçlerde kendini gösterdiği düşünülmektedir. Bu çalışmaların ulaştığı ortak sonuçlar; mekânın dönemin karakteri ile şekillendiği, her dönemin kendi mekânını yarattığı, kültürel eğilimlerin ve kültür davranışının mekân ve mekânsal ilişkilerle somutlaştığı, farklı kültürlerde mekân kullanımında benzerlikler görülse de mekânsal ilişkilerde farklılıkların oluştuğu şeklinde özetlenebilir.

Cumhuriyet ve getirdiği yeniliklerle başlayan gelişme sürecinin etkilerinin, özellikle 1950'li yıllardan itibaren, Gaziantep kentinde de görüldüğü söylenebilir. Bu süreçte, çağdaş yaşamın gerekliliklerinin konut mekânına da yansıdığı, geleneksel konut yapısının yerini modern anlayışla tasarlanan konutlara bıraktı̆̆ı görülür. Çalışma, bu çerçevede Gaziantep'te 1960-1980 dönemi kent konutunun mekân kurgusunun analizi üzerine yoğunlaşmaktadır. Araştırmada, 1960-1980 yılları arasında Gaziantep kenti özelinde görülen sosyokültürel ve sosyoekonomik değişimlerin konut kültürüne ve konutun biçimlenişine etkisinin tespit edilmesi hedeflenmiştir. Bu bakımdan belirlenen dönem içinde konut mekân kurgusundaki değişimlerin belirlenmesi amaciyla mekân dizilimi (space syntax) teknikleri kullanılarak somut veriler elde edilmeye çalışılmıştır. Ayrıca 1960-1980 yılları arasında Gaziantep kent konutunun biçimlenişinde geleneksel ve modern unsurların, plan özelliklerine ve mekân kurgusunda nasıl etki ettiği ve bu unsurların konutu nasıl biçimlendirdiği saptanmak istenmiştir.

4 Yasemin İnce Güney, “Appropriated ‘A la Franga': An Examination of Turkish Modernization Through the Lens of Domestic Culture" (Doktora tezi, University of Michigan, 2005); Onur Erman vd., "Adana'da, 1930’lardan Günümüze, Sosyal, Kültürel ve Ekonomik Değişimler Bağlamında Konut Mimarisinin Gelişimi," (Bilimsel araştırma projesi, Çukurova Üniversitesi BAP Birimi, Proje No: MMF2006BAP5, 2007).

5 Pelin Dursun, “Trabzon Kentsel Dokusunda Morfolojik Analiz” (Doktora tezi, İstanbul Teknik Üniversitesi, 2002). 


\section{Gaziantep Kentinde Mekânsal Değişime Etki Eden Sosyokültürel ve Sosyoekonomik Faktörler}

Nüfus artışı, teknolojik gelişmeler ve beraberinde gelen kentleşme, tüm toplumların yaşam biçiminde değişimlere sebep olan ortak faktörler olarak değerlendirilebilir. Söz konusu faktörlerin, birçok toplumda benzer sorunlara yol açarak konutun yeni şartlar ve ihtiyaçlara göre şekillenmesinde etkili olduğunu söylemek mümkündür. Ancak, temelde insan ihtiyacı ve tercihlerine göre farklılık gösterebilen konut mekânının değişimi incelenirken, insanın içinde yaşadığı toplum ve kültür değerleri ile yöresel öğelerin belirleyici rolü dikkate alınmalıdır. Bunun yanı sıra, bireysel ve toplumsal ölçekte yaşam alışkanlıklarının değişimi, konut kullanıcısının karakter çeşitliliğinin artması gibi çeşitli sosyal ve bireysel belirleyiciler, konut ve konut mekânının farklılaşmasına sebep olmaktadır6. Çalışma kapsamında incelenen Gaziantep kenti 1960-1980 dönemi konut mekânı biçimlenmesinde de sanayi, sosyo-ekonomik yapı ve teknolojideki gelişmeler ile nüfus artışının etkili olduğu düşünülmektedir. Bunun yanı sıra, yerel toplumun yaşam biçiminin değişimi ve bunun etkisiyle aile yapısındaki değişimin yanı sıra diğer sosyal ve bireysel belirleyicilerin konut mekânının biçimlenmesinde önemli derecede etkili olduğunu söylemek mümkündür.

Cumhuriyet'in ilanından sonra ülke genelinde kentlerde üretim faaliyetinin artmasıyla zaman içinde kırsalda tarım cazibesini yitirerek, maddi ve sosyal imkân çeşitliliği sunan kentlere göç başlamıştır. Gaziantep kenti de bu süreçte benzer etkiler altında kalarak değişimlere uğramıştır. Cumhuriyet'in ilk yıllarında kentte kurulan ilk işletmelerin 1932 yılında Velic İplik ve Dokuma Fabrikası, 1934 yılında Pürsefa ve Arıca Un Fabrikaları, 1935 yılında Metanet Un Fabrikası, 1940 yılında Örnek Un Fabrikası, 1945 yılında Dokumacılar Anonim Şirketi olduğu bilinmektedir. 1960'lara kadar gıda ve dokuma endüstrisinin ağırlıklı olduğu kentte, 1961-1969 döneminde plastik endüstri işletmeleri de üretime katılmıştır ${ }^{7}$. Bu etkiler altında kentli nüfus hızla artmaya başlamış, 1950 sonrası göçle gelen düşük gelirli kesim kentin güneyindeki yamaçlara ve kalenin kuzeyinde bulunan Karşıyaka tarafına olmak üzere, kentin çevresine yerleşmiştir. Yüksek gelirli kesim ise kentin batısında bulunan, bahçeli müstakil konutlar ile ağırlıklı olarak apartman tipi konutlardan oluşan kentsel alanları tercih etmiştir ${ }^{8}$. Cumhuriyet'in ilk yirmi yılında, Gaziantep kentinde orta tabaka hızla kuvvetlenmeye başlamış, az gelirli aileler ekonomik durumlarını düzelterek sanayi ve ticari alanda başarı göstermişlerdir. Aynı dönemde, gençlerin birçoğu İstanbul hatta Avrupa'da tahsil yaparak memlekete dönmüştür. Ayrıca orta tabaka, Gaziantep'in siyasi, kültürel ve ekonomik hayatında söz sahibi olmaya başlamıştır?

6 Şengül Öymen Gür, Doğu Karadeniz Örneğinde Konut Kültür (İstanbul: Yem Yayın, 2000), 91-98.

7 İller Bankası, İmar Planlama Dairesi Reisliği, Gaziantep Kent Bütünü Analitik Etüdleri (Ankara: Ofset Fotomekanik Matbaas1, 1972), 45.

8 İller Bankası, İmar Planlama Dairesi Reisliği, Gaziantep Kent Bütünü Analitik Etüdleri, 3-5.

9 Hulusi Yetkin, Gaziantep Tarihi ve Davaları (Gaziantep: Yeni Matbaa, 1968), 65. 
1950'li y1llara gelindiğinde ekonomik anlamda da büyümeye başlayan kentte artan nüfusun kentin sınırlarını zorlamasıyla yeni imar planı hazırlanarak 1955 yılında yürürlüğe girmiştir. Yerleşime açılan yeni kentsel alanlarda modernist tutumdan izler taşıyan yapılar inşa edilmiştir. Öte yandan yeni inşa edilecek yapılar için istenen proje hazırlama zorunluluğuyla, kentteki üst gelir grubuna mensup kişiler, kendi ikametlerine yaptıracakları konutlar için, mimarlık eğitimini tamamlayarak kentte proje üretmeye başlayan mimarlarla çalışmaya başlamışlardır ${ }^{10}$. Modern mimarinin plan ve biçim özellikleri kullanılarak tasarlanan yapılar; form, konstrüksiyon ve cephe özellikleri bakımından kendine özgü tavır sergileyerek, mimari çevrenin şekillenmesinde belirleyici rol oynamıştır.

O döneme dek yapıların genellikle, planlama ve inşayı beraber yürüten taş yapı ustaları tarafından inşa edildiğini söylemek mümkündür. Geleneksel Antep Evleri, aynı avluya ya da sofaya bakan odalardan oluşan, kalabalık ailelerin ikamet edeceği şekilde biçimlenmiştir. Odaların her biri kendi içinde ayrı bir konut niteliği taşımakta ve birkaç kuşak aynı konutta yaşamını ataerkil aile düzeni içinde sürdürmektedir. Değişen sosyo-kültürel ve sosyo-ekonomik yapı kaçınılmaz olarak mevcut aile düzenini etkilemiştir. Aile bireylerinin eğitim seviyesinin yükselmesi, kadınların da erkeklerle birlikte iş ve sosyal hayatın içerisinde daha çok yer almaları, dışa dönük yaşam şeklinin yaygınlaşmasını sağlamış, modernleşmenin gerektirdiği şekilde yaşamını sürdüren bireylerin yeni yaşam alışkanlıkları, mekânı bu yönde biçimlendirmeye başlamıştır. $\mathrm{Bu}$ süreçte kentin yeni gelişen bölgelerinde bahçeli birkaç katlı müstakil konutlar ya da az katlı apartman tipi konutlar inşa edilmiştir. Daha çok ekonomik gücü yüksek aileler tarafından, aile apartmanı biçiminde inşa edilen bu konutlarda, ailenin büyüklerine ve evli çocukların her birine bir daire tahsis edilmesi şeklinde yerleşimler gerçekleşmiştir. $\mathrm{Bu}$ durumun aile bütünlüğünün modern konut düzeninde de devam ettirilmesi çabasının bir göstergesi olduğunu söylemek mümkündür.

Gaziantep kent konutunun ilk örnekleri incelendiğinde, geleneksel yaşam alışkanlıklarının sürdürülmeye çalışıldığı, geleneksel konutta yer alan bazı kullanım alanlarının modern plan şemalarına aktarıldığı söylenebilir. Bu örneklerde konut mekânında daha çok geleneksel mekân karakteristiği gözlemlenirken, batıdaki çözüm ve biçimlere uyum sağlayan cephe özellikleri göze çarpmaktadır. Genellikle bir veya iki katlı bahçeli evlerden oluşan geleneksel Antep Evleri'nde günlük yaşamın nerdeyse büyük bir kısmının geçtiği hayat, apartman konutunda yerini olabildiğince geniş balkonlara bırakmıştır (G. 1). Yerel halkın, özellikle sonbahar aylarında, açık havada yapılmasına gerek duyulan salça, kuruluk, vs. gibi kışa hazırlık faaliyetlerinin kent konutunda gerçekleştirilebilmesine imkân veren mekânlar balkonlar olmuştur. Bu bakımdan çalışma kapsamında incelenen 1960-1980 dönemi Gaziantep kent konutlarındaki balkonların genişliği dikkat çekicidir. Bu durum sıcak iklime sahip Gaziantep kentinde, geleneksel konuttan kalma

10 Şahap Güneyligil, "Piyano Kazandıran Ev", TMMOB Mimarlar Odası Gaziantep Şubesi Mimarlık Bülteni 10 (2007): 6-7. 
"hayat" yaşantısında olduğu gibi, balkon mekânının, âdeta evin bir odası gibi kullanıld1ğını destekler niteliktedir. Mevsimsel özellikleri sebebiyle uzun süre sıcak etkisinde olan kentte, geleneksel konut örneklerinin çoğunda doğal mağaralar bulunduğu bilinmektedir. Eşya ve kışlık yiyecek muhafaza alanı olarak kullanılan bu mağaraların karşıladığı depolama ihtiyacının, apartman konut planında kiler olarak adlandırılan mekânlarla sağlandığı görülür ${ }^{11}$. Geleneksel konutta birçok işlev için kullanılan en temel mekân olan odada bulunan "yüklük" dolab1, apartman konutunda hemen hemen her odada yer alan gömme dolaplarla devam ettirilmiştir. Bununla birlikte kentte inşa edilen ilk apartman konut yapılarının bodrum katında, genelde her daire için bir adet garaj yeri ayrılmıştır. Araç parkı için kullanılan bu mekânın aynı zamanda eve sığdırılamayan fazla eşya ve yiyecek depolama işlevi gördüğü de söylenebilir.

a)

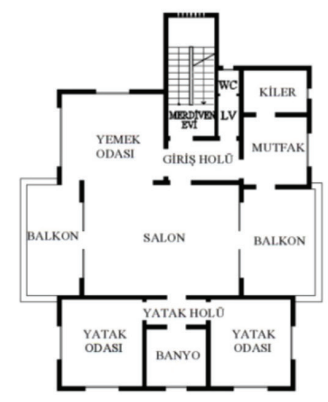

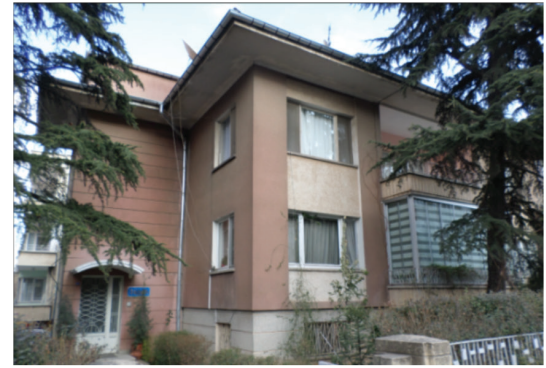
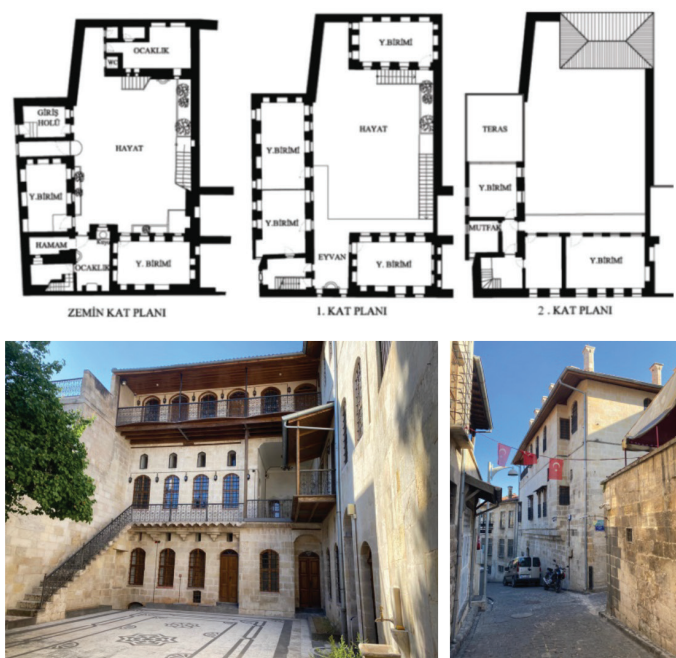

G. 1. a) 1960-1970 dönemi Gaziantep kent konutu örneği (G. 4’ten detay, K1.1 numaralı konut, Esra Kasapbaşı arşivi, 2018)

b) Geleneksel Antep Evi (Plan: Feyza Tatligil, Gaziantep Kentinin Geleneksel Konut Dokusunun ve Sosyokültürel Yapısındaki Değişimin İncelenmesi, 49-52; Fotoğraf: Esra Kasapbaşı arşivi, 2020)

Dolayısıyla yaşam tarzındaki değişimin mimariye yansıması, konut mekânının biçimlenişini ve mekânsal ilişkiler düzenini kaçınılmaz olarak değiştirmiştir. Ancak bu

11 Akten Köylüoğlu, Kadim Şehir Gaziantep (Gaziantep: Neşa Ofset, 2009), 167. 
değişimin, birdenbire ve keskin bir biçimde olmak yerine, geleneksel ve modern unsurların birlikteliğiyle harmanlanarak gerçekleştiği söylenebilir. Geleneksel yaşam alışkanlıklarından kaynaklandığı düşünülen mekânların sürekliliğ̣i, konut biçimlenmesinde yeni arayışların söz konusu olduğu günümüz Gaziantep konutlarında da kullanıcı talebi doğrultusunda ve imar uygulamalarının elverdiği ölçüde, çoğunlukla sağlanmaktadır. Bu durumun; kentin güçlü yaşam kültüründen kaynaklandığı düşünülebilir. Yoğun göç etkisindeki kentte az sayıda kalan yerli ve köklü ailelerin geleneksel yaşam kültüründen kalma bazı alışkanlıkları hâlen devam ettirdiği bugün bile gözlenmektedir.

\section{Gaziantep Kentinde 1960-1980 Dönemi Konut Mekân Kurgusunun Değerlendirilmesi}

Çalışmanın yürütüldüğü Gaziantep kentinde, 1938-1955 döneminde uygulanan ve Hermann Jansen tarafından 1935 yılında hazırlanan ilk kentsel plan doğrultusunda, 1950 'lerden itibaren yeni imar alanları açılmıştır ${ }^{12}$. Kentte bu süreçte imar ve yapı inşa hareketleri hızlanmış, eski kent dokusunun ana arterleri olan yolların genişletilip düzeltilerek genel olarak batı ve güney istikametinde uzatılmasıla yeni cadde ve bulvarlar oluşturulmuştur. Yeni oluşan semtlerdeki mahalleler de araç trafiğine elverişli, doğrusal biçime sahip modern cadde ve bulvarlar arasında gelişmiştir ${ }^{13}$ (G. 2).

a

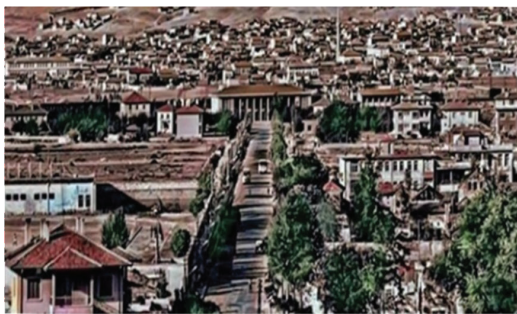

c

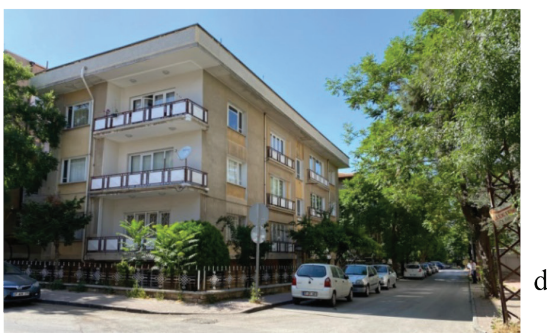

b
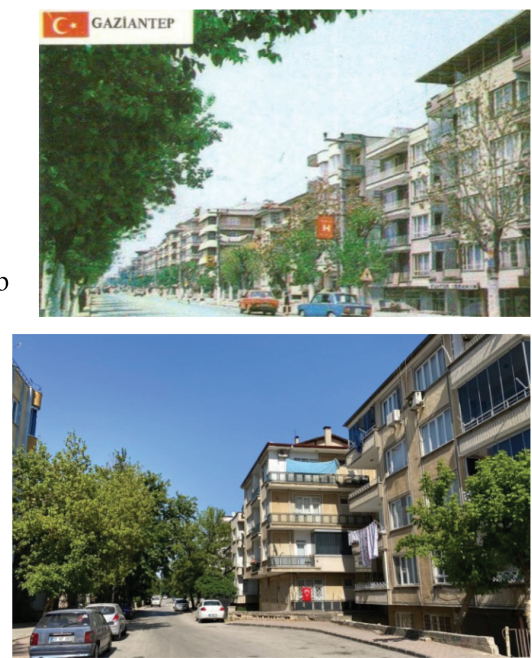

G. 2. a) İstasyon Caddesi, 1960 'lı yılların başı, Jansen Planında yer alan stadyum henüz inşa edilmemiş (Derya Coşkun, Gaziantep'te Konutun Gelişimi, https://www.arkitera.com/gorus/ gaziantepte-konutun-gelisimi/); b) Atatürk Caddesi, 1970'li y1llar; c) ve d) Öğretmenevleri

Mahallesi’nden görüntüler (Esra Kasapbaşı arşivi, 2020).

12 Feyza Kuyucu ve Yasemen Say Özer, "Hermann Jansen'in Planlama İlkelerini Gaziantep Kent Planı Üzerinden Okumak," Mimarlik 409 (2019): 64; M. Serhat Yenice ve Tülay Karadayı Yenice, "Gaziantep Kenti Planlama Deneyimleri Üzerine Bir Süreç Değerlendirmesi," Gaziantep University Journal of Social Sciences 17 (2018): 556; Hermann Jansen'in hazırladığ 1 ve 1938 y1lında uygulamaya alınan Gaziantep Umumi Sehir Planına ait orijinal görsellere Berlin Teknik Üniversitesi, https://architekturmuseum.ub.tu-berlin.de/index. php?set $=1 \& \mathrm{p}=79 \&$ Daten $=154295$ adresinden ulaşılabilir.

13 İller Bankası, İmar Planlama Dairesi Başkanlığı, Gaziantep Tatbikat İmar Planı (1978), 14-17. 
Üst ve orta gelir gruplarına hitap eden, modern anlayışla planlanan dönem konutları genel olarak, Atatürk Bulvarı ve devamındaki Ordu Caddesi aksına paralel biçimde, aksın güneyinde Bahçelievler ve Kolejtepe, kuzeyinde ise Kavaklık, Öğretmenevleri ve Alleben mevkilerinde konumlanmışlardır. Yeni gelişen imarlı parsellerde, ilk örnekleri aile apartmanı şeklinde inşa edilen konutlar, geleneksel Antep evinden hem mekânsal hem de biçimsel olarak farklı niteliktedir. Mekân kurgusu incelemesi yapılan 1960-1980 döneminde Gaziantep’te inşa edilmiş, 10 adet kent konutu söz konusu semtlerde yer almaktadır. Günümüzde kentsel dönüşüm faaliyetlerinin etkisi altında olan bu semtlerde nitelikli pek çok dönem yapısı yıkılmış veya yıkım aşamasındadır. Uygulamaya konu edilen yapıların seçiminde, dönemin mimari karakterini ve yaşam tarzını yansıtır nitelikte olmalarına önem verilmiş, bunun yanı sıra yapıların sağlıklı bir biçimde analizini yapabilmek için, ilgili arşivlerden künye bilgilerine, plan şemalarına ulaşılabilenler tercih edilmiştir. G. 3'de verilen hava fotoğrafında çalışmanın yürütüldüğü bölgeler ve analiz edilen konutların konumları görülmektedir.

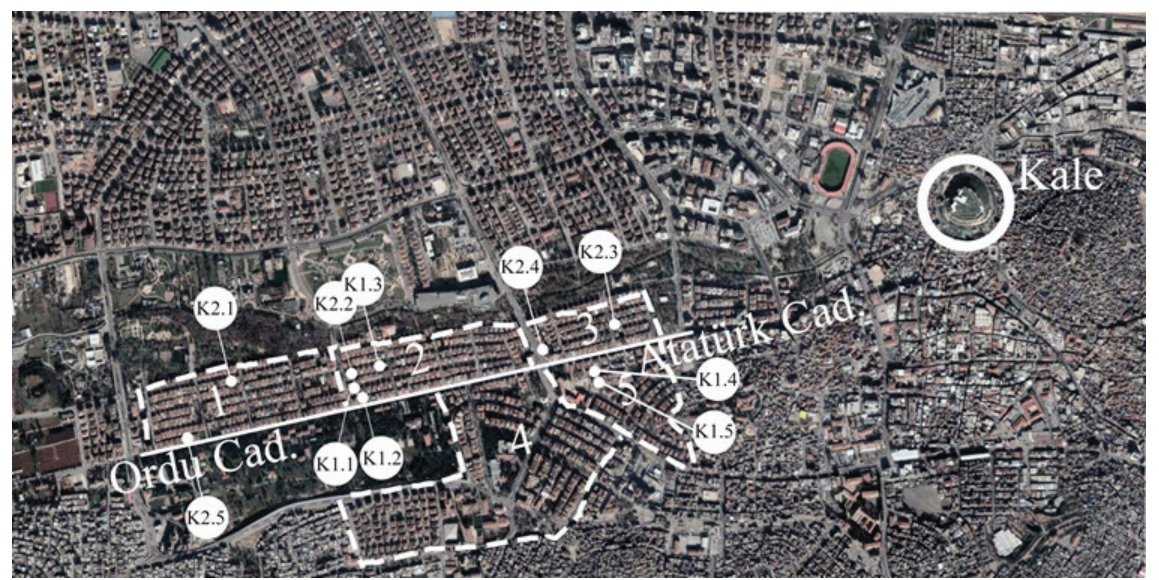

G. 3. Çalışmanın yürütüldüğü bölgeler ve analiz edilen konutların konumu (Google haritalar).

1. Öğretmenevleri, 2. Kavaklık, 3. Alleben, 4. Kolejtepe, 5. Bahçelievler

Araştırma materyalinin belirlenmesi sırasında 1960-1980 yılları arasında inşa edilmiş kent konutlarının değişimini daha açık bir biçimde belirleyebilmek ve geçerli bir karş1laştırma yapabilmek amacıyla konutlar on yıllık periyotlar içinde gruplanmıştır. Yapılan gruplama sonucunda her bir dönem içinde konutların benzer niteliklere sahip olduğu söylenebilir. Ana hatlarıyla bakıldığında; 1960-1970 dönemi konut yapıları genel olarak ayrık nizamda, üç katlı, ilk beş yıllık süreçte her katta tek daire şeklinde plan çözümüne sahiptir. 1970-1980 dönemi konut yapıları ise, genel olarak beş kata kadar, ayrık üç kat yapı nizamında, her katta iki ya da üç daire şeklinde plan şemalarına sahiptir.

Bu durumda daha çok müstakil aile apartman konutlarının görüldüğü 1960-1970 dönemi ve apartmanlaşmanın başladığı 1970-1980 dönemi olmak üzere, iki tarih aralığında incelenen Gaziantep kent konutlarına ait genel bilgiler aşağıda verildiği gibidir (G. 4): 


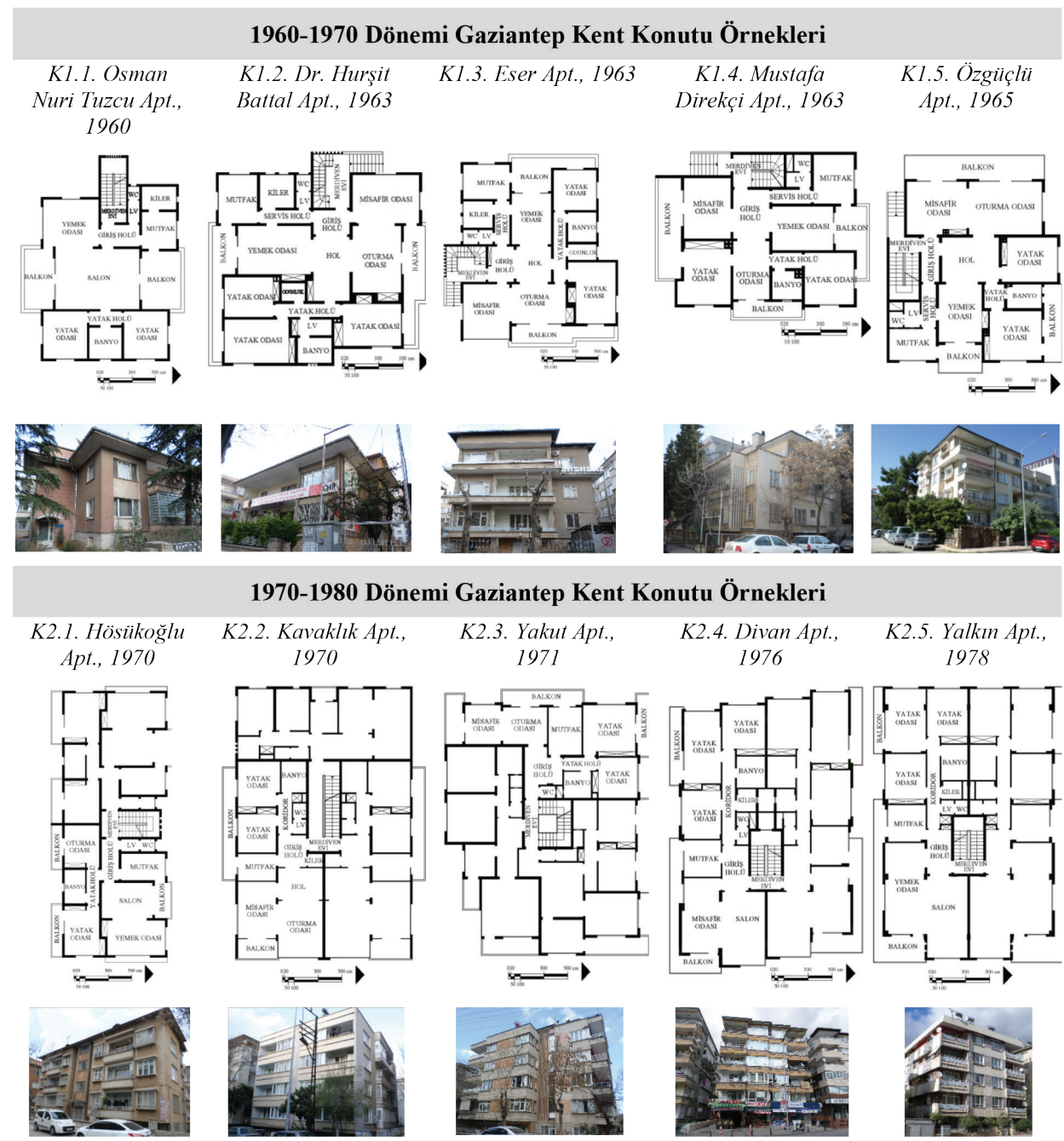

G. 4. Mekân kurgusu analizi yapılan 1960-1980 dönemi Gaziantep kent konutları

(Esra Kasapbaşı arşivi, 2018)

Çalışmanın hedefleri doğrultusunda konut mekân kurgusunu analiz etmek ve mekânsal ilişkileri sayısal verilere dönüştürmek amacıyla Mekân Dizilimi Analizi (Space Syntax Analysis) yöntemi kullanılmıştır. Bir "mekân okuma yöntemi” olarak kabul edilen ve 1970'lerin başlarında Bill Hillier ve ekibi tarafından geliştirilen yöntem gerek yapının gerekse yapılı çevrenin mekânsal ilişki karakteristiğini oluşturan fonksiyonel, mekânsal ve biçimsel etkileri tanımlamak üzerine yoğunlaşmıştır ${ }^{14}$.

14 H. Meltem Gündoğdu, "Mekan Dizimi Analizi Yöntemi ve Araştırma Konuları,” Art-Sanat 2 (2014): 255, erişim 7 Temmuz 2019, https://dergipark.org.tr/en/download/article-file/92900; Mekân kurgusunun tanımlanmas1, mekânsal ilişkilerin değişimiyle oluşan farklı kurguların yorumlanması için bkz. Bill Hillier, Julienne Hanson ve Hilliaire Graham, "Ideas are in Things," Environment and Planning B: Planning and Design 14 (1987): 363-385; Mekân dizilimi analizinde temel kavramların anlaşılması ve analizde kullanılacak temel teknikler için bkz. Sonit Bafna, "A Brief Introduction to Its Logic and Analytical Techniques," Environment and Behavior 
Yapıları, bir bütünü oluşturmak üzere mekânların bir araya gelmesiyle kurgulanmış ilişkiler ağı şeklinde yorumlayan Hillier ve Hanson; yapılı çevrenin sosyal yapının bir yansıması olduğunu, somut olarak görülemeyen toplumsal yaşama ve toplumsal kurallara ait birtakım unsurların fiziksel çevrede somutlaştığını belirtmektedir ${ }^{15}$. Bu bakımdan mekân dizilimi analizi, yapılı çevredeki mekânsal ilişki biçimlerinin sosyal çevreyle olan etkileşimlerini analiz etmek için uygun bir yöntem olarak sunulmaktadır. Bill Hillier ve Jullienne Hanson tarafından geliştirilen mekân dizilimi analizi teknikleri, 1980'li yıllarda The Social Logic of Space isimli kitapta aktarılmıştır.

Özetle, günümüzde mimarlık, kentsel tasarım, arkeoloji gibi birçok alanda gerçekleştirilen çalışmalarda mekân dizilim analiz tekniklerinin kullanıldığı görülmektedir. Yapılı çevreyi oluşturan mekânsal dokunun; yerleşim veya konut ölçeğinde, matematiksel, grafiksel vb. anlatımlar yoluyla çözümlenerek, somut bir dille ifade edilmesi, mekân dizilimi yönteminin temelini oluş̧urmaktadır.

Çalışmada mekân dizilimi analizleri, Alasdair Turner ve Eva Friedrich tarafından 2000-2011 y1lları arasında geliştirilen Depthmap X paket programı kullanılarak yapılmıştır ${ }^{16}$. Mekân dizilimi yöntemi kullanılarak, çalışma kapsamında gerçekleştirilen analizler şu şekildedir:

a) Adım Derinliği (Step Depth) Analizi: Mekânların işlevsel gruplanışını çözümlemek ve mekânsal ilişki kurgusunu anlamak amacıyla adım derinliği (step depth) analizleri yapılmıştır. Analizlerin tümünde merdiven holü, kök mekân olarak kabul edilerek mekânların adım derinlik değerleri bulunmuş, ardından her bir konut için ortalama adım derinliği hesaplanmıştır. Bu analiz yardımıyla geçiş diyagramı üzerinde ortalama derinlik değerleri işaretlenerek derinde ya da yüzeyde kalan mekânlar belirlenmeye çalışılmıştır. Mekânın derinde olmasının mahrem ve özel kullanımla, yüzeyde olmasının ise mahremiyet düzeyi düşük ve genel kullanımla ilişkili olduğu kabul edilerek mekânların derinlik değerleri yorumlanmaya çalışılmıştır.

Ortalama derinlik değeri hesabında Hillier ve Hanson'un yöntemine dayanarak ilk önce geçiş modelinde seçilen her adımda yer alan mekân sayısı, adım derinliği ile çarpılır ${ }^{17}$. Ardından elde edilen değerler toplanarak toplam mekân sayısının bir

35 (2003): 17-29; Mekân dizilimi analizinin kuramsal temeli için bkz. Bill Hillier, "Space Syntax as a Method and as a Theory," $21^{\text {st }}$ International Seminar on Urban Form - ISUF2014, Porto, Portugal, 3-6 Temmuz 2014; Mekânda topolojik ve geometrik ilişkilerin mekân dizilimi analiziyle değerlendirilmesi ve yorumlanması için bkz. John Peponis ve Jean Wineman, "Spatial Structure of Environment and Behavior," Handbook of Environmental Psychology, ed. Robert B. Bechtel ve Azra Churchman (New York: John Wiley \& Sons, 2002), 271-291; Mekân konfigürasyonunun analizinde konveks mekân analizleri ve değerlendirmeleri için bkz. John Peponis vd., "On the Description of Shape and Spatial Configuration Inside Buildings: Convex Partitions and Their Local Properties," Environment and Planning B: Planning and Design 24 (1997): 761-781.

15 Bill Hillier ve Jullienne Hanson, The Social Logic of Space (Cambridge: University Press, 1984), 4-8.

16 depthmapX, erişim 12 Ağustos 2019, https://www.ucl.ac.uk/bartlett/architecture/research/space-syntax/depthmapx

17 Hillier ve Hanson, The Social Logic of Space, 149-152. 
eksiğine bölünür (G. 5). Elde edilen sonuçlar, en derindeki ya da en sığ durumdaki mekânların tespit edilmesini, mekânsal hiyerarşinin anlaşılmasını, dönem içinde ya da dönemler arasında mekânsal derecelenmede benzerlik ve farklılıkların belirlenmesini sağlamıştır.

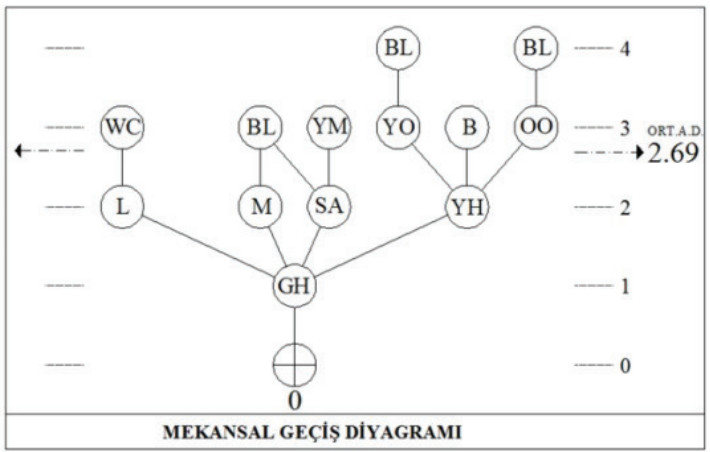

\begin{tabular}{|c|c|c|c|c|}
\hline ADIM & & $\begin{array}{l}\text { MEKAN } \\
\text { SAYISI }\end{array}$ & & \\
\hline 4 & $\mathrm{x}$ & 2 & $=$ & 8 \\
\hline 3 & $\mathrm{x}$ & 6 & $=$ & 18 \\
\hline 2 & $\mathrm{x}$ & 4 & $=$ & 8 \\
\hline 1 & $\mathrm{x}$ & 1 & $=$ & 1 \\
\hline 0 & $\mathrm{x}$ & 1 & $=$ & 0 \\
\hline \multicolumn{5}{|c|}{$=$} \\
\hline \multicolumn{5}{|c|}{$\begin{array}{l}\text { Ortalama Adım Derinliği }=\frac{35}{13}=2.69 \\
(\text { ORT.A.D. }) \quad(14-1)\end{array}$} \\
\hline
\end{tabular}

G. 5. Örnek bir geçiş modeli ve adım derinliği hesaplama tablosu ${ }^{18}$

b) Geçiş Diyagramı (J-Graph) Analizi: Mekânsal geçişleri belirlemek, adım derinliklerine göre bir mekânın diğerine olan adım uzaklığını anlamak ve görselleştirmek için geçiș diyagramı modelleri hazırlanmıștır. Geçiș diyagramlarında her bir mekân bir düğüm noktasıyla, mekânların birbiriyle ilişkisi ise bağlantı çizgileri ile gösterilmiştir. Çizgilerin uzunluğunun modelde bir anlamı yoktur.

Geçiş modellerinde mekânsal ilişki düzenlerini Hillier; a-tip, b-tip, c-tip, d-tip olmak üzere dörde ayırmaktadır ${ }^{19}$ (G. 6).

i) a-tipi mekânsal ilişkide mekânın sadece bir adet bağlantısı vardır.

ii) b-tipi mekânsal ilişside mekânın birden fazla bağlantısı vardır. Bu ilişki düzeninde orijine aynı mekândan geçerek dönülür.

iii) c-tipi mekânsal ilişkide mekân bir halka üzerinde bulunur. Orijine farklı bir mekândan geçerek geri dönülür.

iv) d-tipi mekânsal ilişkide mekân halkalar arasında yer alır. Böylece mekân, rota değişimini sağlayarak halkalar arasında geçișe olanak tanır. Orijine farklı mekân gruplarının oluşturduğu halkalardan geçerek geri dönülebilir.

Hanson özellikle d-tipi ilișki düzeninde halkaların kesişim noktasında yer alan mekânların farklı kullanıcı gruplarının bir araya gelmesini sağladığını ve güçlü mekân olarak adlandırdığı bu mekânların kurguda farklı ve önemli bir işleve veya kullanıcıya ait olabileceğini belirtir ${ }^{20}$.

18 Onur Erman ve Esra Kasapbaşı tarafından çalışmanın sonuçlarından üretilmiştir.

19 Bill Hillier, Space is the Machine (London: Space Syntax, 2007), 250-251.

20 Julienne Hanson, Decoding House and Homes (Cambridge: University Press, 1998), 278-279. 


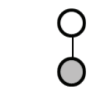

a-tipi ilişki

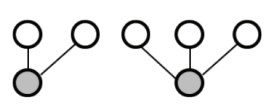

b-tipi ilişki
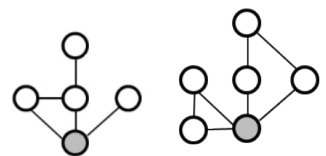

c-tipi ilişki

d-tipi ilişki

G. 6. Geçiş modelleri mekânsal ilişki düzenleri

(Bill Hillier, Space is the Machine, 250-251, uyarlama).

Mekânsal ilişki düzenine göre farklı geçiş modelleri oluşmakla birlikte ağaç ve çalı formlu olmak üzere iki temel geçiş modelinden söz edilebilir. Bu temel modeller halkalı, sı ̆̆ ve derin olarak çeşitlenebilir ${ }^{21}$. Modelin ağaç ya da çalı formunu a ve b tipi ilişkilerin, sığ ya da derin olmasını ise c ve d tipi ilişkilerin belirlediği söylenebilir. Derin ağaç formu modellerde, mekânsal kontrol yüksek ve mekân hiyerarşisi fazladır. Bu modellerde asimetrik yapıyla birlikte derinlik artar. Sı̆̆ ağaç formu ise bağlantı şekillerinin çeşitlendiği durumlarda görülür. Bu modellerde mekâna halkaların dâhil olmasıyla beliren alternatif rotalar simetrik yapının oluşmasını sağlar ve geçiş modelinde derinliğin azalmasına neden olur ${ }^{22}$ (G. 7). Bu bakımdan mekânların, bağlantı sayıları ve şekilleri geçiş modellerini biçimlendirirken aynı zamanda mekânsal ilişkilere bağlı olarak mekânsal kullanımı da tanımlar.
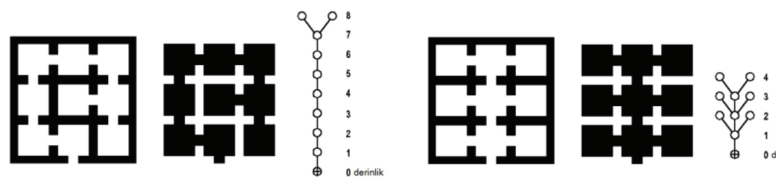

b) sığ ă̆aç formlu geçiş modeli
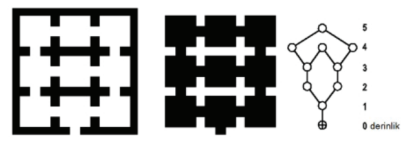

c) sı ̆̆ halkalı geçiş modeli

a) derin ağaç formlu geçiş modeli

eri ve kök mekâna göre geçiş modelinin değişimi (Bill Hillier,

G. 7. Farklı geçiş modeli örnekleri ve kök mekâna göre geçi
Space is the Machine, 21).

Mekân dizilimi analizi kapsamında konut içi mekânlar işlevsel niteliğine ve kullanıcısının özelliğine göre gruplanmıştır. Konut içi mekân gruplarına ilişkin geçiş diyagramı analizi sonuçlarına dayanarak kurgudaki değişim gözlenmeye çalışılmıştır. Buna göre mekânsal gruplar şu şekilde sıralanabilir:

a) Konut dışı kullanıcı mekânları: Konutun hane halkından olmayan kişiler tarafindan konut kullanıcısıyla birlikte kullanılabilen, oturma, dinlenme gibi günlük yaşam aktivitelerini gerçekleştirdiği mekânlar olarak kabul edilmiştir. Planlar üzerindeki isimlendirilme şekilleri konutlara göre farklılık gösteren bu mekânlar, konutun mahremiyet bakımından genel kullanım alanları olarak kabul edilmiş olup oturma odası, misafir odası, yemek odası ve salonu içermektedir.

21 Hillier, Space is the Machine, 23.

22 Onur Erman, "Mekansal Komşuluk Kavramı Üzerinden Mimari Mekanın Analizi,” Çukurova Üniversitesi Mühendislik Mimarlık Fakültesi Dergisi 32 (2017): 168. 
b) Konut içi kullanıcı mekânları: Konutun asıl kullanıcısına ait ve özel kullanım alanları olarak kabul edilmiştir. Bu bölüm yatak odalarını kapsamaktadır. Mahremiyet düzeyi konutun diğer bölümlerinden yüksek olan bu mekânların, konutun hane halkından olmayan kişiler tarafından kullanımının olmadığı varsayılmaktadır.

c) Servis mekânları: Konutta yemek hazırlama ve depolama işlevlerinin gerçekleştirildiği mutfak ve kilerle birlikte, genel olarak konutun girişine yakın konumda bulunan lavabo-wc ve banyo gibi hijyen alanlarını kapsamaktadır.

d) Holler ve bağlantı mekânları: İlk üç maddede gruplandırılan mekânlarla işlev birliği doğrultusunda bağladığı mekânların bir uzantısı gibi değerlendirilen holleri (servis holü, yatak holü, vs.) birbiriyle ilişkilendiren, hol, koridor, v.s. mekânlar ile, konutun giriş mekânı olan giriş holünü (antre) kapsamaktadır.

Yukarıda açıklanan analizler yardımıyla dönemlere göre gruplanmış her bir konut için mekân sayısı, geçiş modeli derinliği, adım derinliği ortalama değeri, konutun mekânsal geçiş modeli diyagramı, modelde oluşan halka sayısı ve rota değiştiren mekân sayısı belirlenmeye çalışılmıştır. Rota değiştiren mekânlar geçiş modeli diyagramlarında koyu renkle işaretlenerek belirtilmiştir. Ayrıca elde edilen değerlere göre ortalamanın üzerinde derinliğe sahip mekânların yanı sıra en derin ve en sı̆̆ mekânların tespiti yapılmıştır. Dönemlere göre ulaşılan bulgular aşağıda verildiği şekilde değerlendirilmeye çalışılmıştır.

\section{0-1970 dönemi Gaziantep kent konutu örneklerinde:}

Mekân sayısının 14 ile 20 arasında değiştiği, ardışık holler ile mekânların ilişkilendirildiği, mekânlar arası geçişlerde kademelendirmenin fazla olduğu görülmüştür. Mekânsal geçiş modelleri, halkalı sığ ağaç formunda ve geçiş modeli derinliği 4 (T. 1/K1.1, K1.3, K1.4) ve 5 (T. 1/K1.2, K1.5) adım olarak belirlenmiştir. Konutlarda mekânların adım derinliği ortalama değerinin daha çok 3'ün üzerinde (T. 1/K1.2, $\mathrm{K} 1.3$, K1.5) olduğu görülmüş, sadece iki örnekte (T. 1/K1.1, K1.4) adım derinliği ortalama değeri 3 'ün altında bulunmuştur. Halka sayılarının da benzer şekilde en çok K1.2, K1.3 ve K1.5'de, en az K1.4'de bulunduğu tespit edilmiştir (T. 1). En çok rota değiştiren mekân sayısı K1.2 ve K.1.5 şemalarında, en az rota değiştiren mekân sayısı ise K1.1 ve K1.4 şemalarında yer almıştır (T. 1, G. 8). Bu değerlendirmeye göre halka sayısı ve rota değiştiren mekân sayısı düşük olan örneklerde adım derinliğinin de düşük olduğu açıkça belirmektedir. 
Tablo 1

1960-1970 Dönemi Gaziantep kent konutu örneklerinin mekân dizilimi analizi verileri ${ }^{23}$

\begin{tabular}{|c|c|c|c|c|c|c|c|c|c|c|}
\hline $\begin{array}{l}\text { Ev } \\
\text { No }\end{array}$ & $\begin{array}{c}\text { Mekân } \\
\text { Sayısı }\end{array}$ & $\begin{array}{l}\text { Geçiş } \\
\text { Model } \\
\text { Derin. }\end{array}$ & $\begin{array}{c}\text { Adım } \\
\text { Derin. } \\
\text { Ort. }\end{array}$ & $\begin{array}{c}\text { Geçiş } \\
\text { Modeli }\end{array}$ & $\begin{array}{l}\text { Halka } \\
\text { Sayısı }\end{array}$ & $\begin{array}{c}\text { Rota } \\
\text { Değiş. } \\
\text { Mekân } \\
\text { Sayısı }\end{array}$ & $\begin{array}{c}\text { Rota } \\
\text { Değişt. } \\
\text { Mekânlar }\end{array}$ & $\begin{array}{l}\text { Ortalama } \\
\text { Üstü } \\
\text { Derinlikteki } \\
\text { Mekânlar }\end{array}$ & $\begin{array}{c}\text { En Derin } \\
\text { Mekânlar }\end{array}$ & $\begin{array}{l}\text { En Sı̆̆ } \\
\text { Mekân }\end{array}$ \\
\hline K1.1 & 14 & 4 & 2,77 & $\begin{array}{c}\text { dallanmış } \\
\text { halkalı sığ } \\
\text { ağaç } \\
\end{array}$ & 3 & 3 & $\begin{array}{c}\text { GH/YM } \\
\text { /SA }\end{array}$ & $\begin{array}{c}\mathrm{BL} 1 / \mathrm{YH} / \\
\mathrm{BL} 2 / \mathrm{K} / \mathrm{WC} / \\
\mathrm{YO} 1 / \mathrm{B} / \mathrm{YO} 2\end{array}$ & $\mathrm{YO} 1 / \mathrm{B} / \mathrm{YO} 2$ & $\mathrm{GH}$ \\
\hline $\mathrm{K} 1.2$ & 20 & 5 & 3,21 & $\begin{array}{l}\text { dallanmış } \\
\text { halkalı sığ } \\
\text { ağaç }\end{array}$ & 4 & 6 & $\begin{array}{c}\mathrm{GH} / \mathrm{H} / \\
\mathrm{SH} / \mathrm{YM} / \\
\mathrm{OO} / \mathrm{MO}\end{array}$ & $\begin{array}{c}\mathrm{WC} / \mathrm{BL} 1 / \mathrm{OD} / \\
\mathrm{YO} 1 / \\
\mathrm{YO} 2 / \mathrm{L} 2 / \\
\mathrm{YO} 3 / \mathrm{B}\end{array}$ & B & $\mathrm{GH}$ \\
\hline K1.3 & 18 & 4 & 3,12 & $\begin{array}{l}\text { dallanmış } \\
\text { halkalı sığ } \\
\text { ağaç }\end{array}$ & 4 & 5 & $\begin{array}{c}\mathrm{GH} / \mathrm{H} / \\
\mathrm{SH} / \mathrm{YM} / \\
\mathrm{OO} \\
\end{array}$ & $\begin{array}{c}\mathrm{WC} / \mathrm{BL} 2 / \\
\mathrm{YO} 2 / \mathrm{B} / \mathrm{OD} / \\
\mathrm{YO} 1 / \mathrm{BL} 1 \\
\end{array}$ & $\begin{array}{c}\mathrm{WC} / \mathrm{BL} 2 / \\
\mathrm{YO} 2 / \mathrm{B} / \mathrm{OD} / \\
\mathrm{YO} 1 / \mathrm{BL} 1\end{array}$ & $\mathrm{GH}$ \\
\hline K1.4 & 16 & 4 & 2,8 & $\begin{array}{l}\text { dallanmış } \\
\text { halkalı sığ } \\
\text { ağaç }\end{array}$ & 2 & 1 & $\mathrm{GH}$ & $\begin{array}{c}\mathrm{BL} 1 / \mathrm{YO} 1 / \\
\mathrm{BL} 2 / \mathrm{YH} / \\
\mathrm{BL} 3 / \mathrm{M} / \mathrm{L} / \mathrm{B} / \\
\mathrm{YO} 2 / \mathrm{WC}\end{array}$ & $\mathrm{B} / \mathrm{YO} 2 / \mathrm{WC}$ & $\mathrm{GH}$ \\
\hline K1.5 & 17 & 5 & 3,06 & $\begin{array}{l}\text { dallanmış } \\
\text { halkalı sığ } \\
\text { ağaç }\end{array}$ & 4 & 6 & $\begin{array}{c}\mathrm{GH} / \mathrm{H} / \mathrm{SH} \\
/ \mathrm{YM} / \mathrm{OO} / \\
\mathrm{MO}\end{array}$ & $\begin{array}{c}\mathrm{B} / \mathrm{YO} 2 / \mathrm{BL} 2 / \\
\mathrm{WC} / \mathrm{BL} 3\end{array}$ & BL3 & $\mathrm{GH}$ \\
\hline
\end{tabular}

Adım derinliği değerlerine göre ortalamanın üzerinde değere sahip olup dizimsel bakımdan daha derinde bulunan mekânların yatak odası, banyo gibi mahremiyet mekânlarını içeren ve daha çok konut içi kullanıcının bulunduğu yatma (gece) bölümü mekânları ile balkonlar olduğu saptanmıştır.

1960 -1970 Dönemi Konut

Örneklerinin Geçiş Modeli

Diyagramları

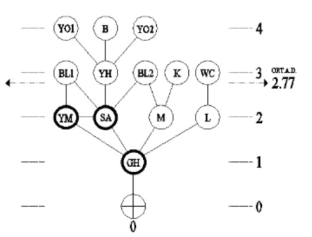

K1.2 Osman Nuri Tuzcu Apt. 1960

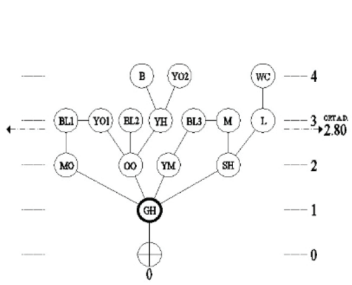

K1.4. Mustafa Direkçi Apt., 1963

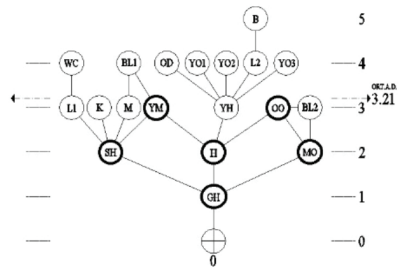

K1.2. Dr. Hurşit Battal Apt., 1963

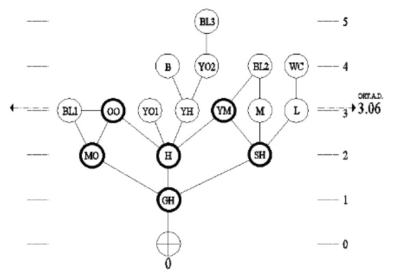

K1.5. Özgüçlü Apt., 1965
K1.3. Eser Apt., 1963

$=3^{\rightarrow 3.12}$

$-2$

$-1$

$-0$

G. 8. 1960-1970 Dönemi Gaziantep kent konutu örneklerinin geçiş modeli diyagramları ${ }^{24}$

23 Onur Erman ve Esra Kasapbaşı tarafından çalışmanın sonuçlarından üretilmiştir.

24 Onur Erman ve Esra Kasapbaşı tarafından çalışmanın sonuçlarından üretilmiştir. 
Geçiş modellerinin tümünde a-tipi, b-tipi, c-tipi ve d-tipi mekânsal ilişki düzeni bulunmaktadır. Rota değiştiren mekânların (d-tipi ilişkili) en çok; giriş holü (GH), hol $(\mathrm{H})$, servis holü (SH), yemek odası (YM), oturma odası (OO), misafir odas1 (MO) olduğu görülmüştür. Mekânsal gruplara göre değerlendirildiğinde ise rota değiştiren mekânların holler ve bağlantı mekânları (GH, H, SH) ile konut dışı kullanıcı mekânları (YM, OO, MO) grubunda yer aldığı belirlenmiştir. Özellikle K1.2, K1.3 ve K1.5 gibi çok halkalı şemalarda (G. 8), rota değiştiren mekânların daha çok konut dışı ve konut içi kullanıcı gruplarının bir arada bulunabildiği, aynı zamanda konut içi dolaşımın da kontrol edilebildiği mekânlar olduğu tespit edilmiştir. Bu sonuç; rota değiştiren mekânlarda dolaşımın daha fazla, konut içi mahremiyet düzeyinin daha düşük olduğuna işaret etmektedir.

Geçiş modeli diyagramlarında dikkat çeken bir diğer bulgu da mutfağın şemalarda tekrar ettiği görülen ilişki kurgusudur. Bu dönem konutlarında mutfağın mutlaka kiler ve yemek odası ile ilişkili olduğu, kiler ile ilişkisinin doğrudan veya servis holüyle, yemek odasıyla ilişkisinin ise servis holünün yanı sıra balkonla da (G. 8/K1.1, K1.2, K1.3, K1.4, K1.5) kurulduğu görülmüştür.

\section{0-1980 dönemi Gaziantep kent konutu örneklerinde:}

Mekân sayısının 13 ile 15 arasında değiştiği, ardışık hol sayısının azaldığı, mekânların koridor etrafında sıralanarak ilişkilendirildiği, dallanmış sığ ağaç (T. 2/ K2.1, K2.2, K2.3) formunda olan mekânsal geçiş grafiklerinde bir önceki döneme göre daha basit bir ilişki düzeninin oluştuğu görülmüştür. Mekânlar arası ilişkilere ve geçişlere bağlı olarak, kurgularda tek halka oluşmuş (T. 2/K2.1, K2.2, K2.3) ve rota değiştiren mekân sayısı belirgin şekilde azalmıştır. Bu durumun temel fonksiyonlar aynı kalsa bile, mekânlar arasında alternatif geçişleri oluşturan bazı mekânsal ilişkilerin 1970-1980 dönemi konutlarında yer almamasından kaynaklandığı söylenebilir (T. 2, G. 9).

Geçiş modeli derinliğinin 4 olduğu 1970-1980 dönemi konutlarının tümünde, adım derinliği ortalama değeri 3'ün altındadır. Bu dönem konutlarının geçiş modellerinin tamamında a-tipi, b-tipi ve c-tipi mekânsal ilişki düzeni olduğu görülmüş, rota değiştiren mekânları ifade eden d-tipi mekânsal ilişki düzeni sadece K2.4 ve K2.5 şemalarında tespit edilmiştir.

Bu dönemde rota değiştiren mekânlar, holler ve bağlantı mekânları grubundan sadece giriş holü $(\mathrm{GH})$ ve konut dışı kullanıcı mekânları grubundan misafir odası (MO) ve yemek odası (YM) olmuştur. Ortalama derinlik değeri üzerinde değere sahip olup dizimsel olarak daha derinde olan mekânların daima yatak odası, banyo gibi mahremiyet düzeyi yüksek, konut içi kullanıcı mekânları olduğu görülmüştür. 
Tablo 2

1970-1980 Dönemi Gaziantep kent konutu örneklerinin mekân dizilimi analizi verileri ${ }^{25}$

\begin{tabular}{|c|c|c|c|c|c|c|c|c|c|c|}
\hline $\begin{array}{l}\text { Ev } \\
\text { No }\end{array}$ & $\begin{array}{c}\text { Mekân } \\
\text { Sayısı }\end{array}$ & $\begin{array}{l}\text { Geçiş } \\
\text { Model } \\
\text { Derin. }\end{array}$ & $\begin{array}{l}\text { Adım } \\
\text { Derin. } \\
\text { Ort. }\end{array}$ & $\begin{array}{c}\text { Geçiş } \\
\text { Modeli }\end{array}$ & $\begin{array}{l}\text { Halka } \\
\text { Sayısı }\end{array}$ & $\begin{array}{c}\text { Rota } \\
\text { Değiş. } \\
\text { Mekân } \\
\text { Sayısı }\end{array}$ & $\begin{array}{c}\text { Rota } \\
\text { Değişt. } \\
\text { Mekânlar }\end{array}$ & $\begin{array}{l}\text { Ortalama Üstü } \\
\text { Derinlikteki } \\
\text { Mekânlar }\end{array}$ & $\begin{array}{l}\text { En Derin } \\
\text { Mekânlar }\end{array}$ & $\begin{array}{l}\text { En Sı̆̆ } \\
\text { Mekân }\end{array}$ \\
\hline K2.1 & 14 & 4 & 2,69 & $\begin{array}{c}\text { dallanmış } \\
\text { sığ ağaç }\end{array}$ & 1 & - & - & $\begin{array}{c}\mathrm{WC} / \mathrm{BL} 1 / \mathrm{YM} / \\
\mathrm{YO} / \mathrm{B} / \mathrm{OO} / \mathrm{BL} 2 / \\
\mathrm{BL} 3\end{array}$ & $\begin{array}{c}\mathrm{YO} 1 / \mathrm{B} / \\
\mathrm{YO} 2\end{array}$ & $\mathrm{GH}$ \\
\hline K2.2 & 15 & 4 & 2,71 & $\begin{array}{c}\text { dallanmış } \\
\text { sığ ağaç }\end{array}$ & 1 & - & - & $\begin{array}{c}\mathrm{OO} / \mathrm{MO} / \mathrm{BL} 2 / \\
\mathrm{YO} 1 / \mathrm{YO} 2 / \mathrm{B} / \mathrm{L} / \\
\mathrm{BL} 1 / \mathrm{WC} \\
\end{array}$ & B & $\mathrm{GH}$ \\
\hline K2.3 & 13 & 4 & 2,67 & $\begin{array}{c}\text { dallanmış } \\
\text { sığ ağaç }\end{array}$ & 1 & - & - & $\begin{array}{c}\mathrm{MO} / \mathrm{BL} 2 / \mathrm{YO} 1 / \\
\mathrm{YO} 2 / \mathrm{B} / \mathrm{BL} 1 / \mathrm{BL} 3\end{array}$ & $\begin{array}{c}\mathrm{WC} / \mathrm{BL} 2 / \\
\mathrm{YO} 2 / \mathrm{B} / \mathrm{OD} / \\
\mathrm{YO} 1 / \mathrm{BL} 1 \\
\end{array}$ & GH \\
\hline K2.4 & 15 & 4 & 2,71 & $\begin{array}{l}\text { dallanmış } \\
\text { halkalı sığ } \\
\text { ağaç }\end{array}$ & 2 & 2 & $\mathrm{GH} / \mathrm{MO}$ & $\begin{array}{c}\mathrm{BL} 1 / \mathrm{YO} 1 / \mathrm{YO} 2 / \\
\mathrm{YO} 3 / \mathrm{B} / \mathrm{K} / \mathrm{L} / \mathrm{BL} 2 / \\
\mathrm{WC}\end{array}$ & $\mathrm{B} / \mathrm{YO} 2 / \mathrm{WC}$ & $\mathrm{GH}$ \\
\hline $\mathrm{K} 2.5$ & 15 & 4 & 2,71 & $\begin{array}{l}\text { dallanmış } \\
\text { halkalı sığ } \\
\text { ağaç }\end{array}$ & 2 & 2 & $\mathrm{GH} / \mathrm{YM}$ & $\begin{array}{c}\mathrm{BL} 1 / \mathrm{YO} 1 / \mathrm{YO} 2 / \\
\mathrm{YO} 3 / \mathrm{B} / \mathrm{K} / \mathrm{L} / \mathrm{BL} 2 / \\
\mathrm{WC}\end{array}$ & BL3 & $\mathrm{GH}$ \\
\hline
\end{tabular}

Geçiş modellerinde önceki dönemde dikkat çeken kiler, mutfak ve yemek odası ilişkisinin bu dönemde değişerek devam ettiği gözlenmiştir. Her ne kadar mutfağın yemek odasıyla olan ilişkisi korunsa da kilerin mutfakla olan ilişkisi zayıflamış (G. 9/K2. 2, K2. 4) ya da kiler mekânı kurgudan çıkarılmıştır (G. 9/K2. 1, K2. 3, K2. 5). Benzer şekilde önceki dönemde şemalarda bu mekânları birbirine bağlayan servis holü de bu dönemde kaybolarak, yemek odası mutfak ilişkisini sağlama görevini balkon üstlenmiştir.

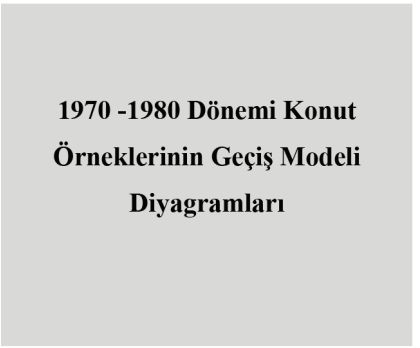

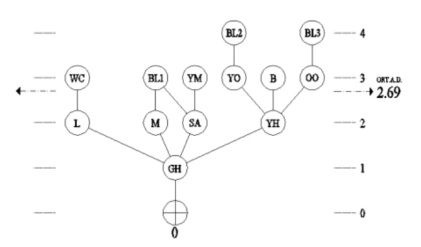

K2.1. Hösükoğlu Apt., 1970

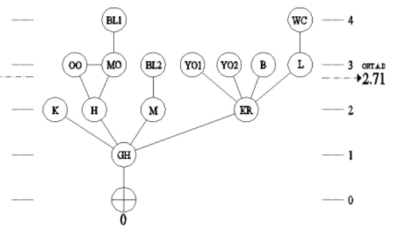

K2.2. Kavaklık Apt., 1970

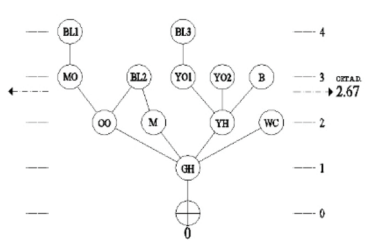

K2.3. Yakut Apt., 1971

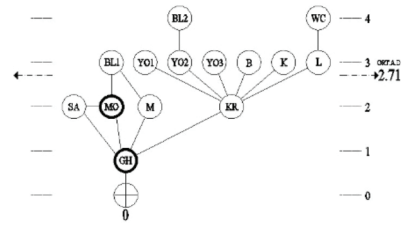

K2.4. Divan Apt., 1976

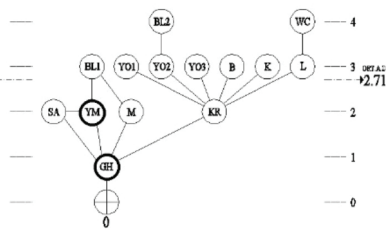

K2.5. Yalkın Apt., 1978

G. 9. 1970-1980 Dönemi Gaziantep kent konutu örneklerinin geçiş modeli diyagramları ${ }^{26}$

25 Onur Erman ve Esra Kasapbaşı tarafından çalışmanın sonuçlarından üretilmiştir.

26 Onur Erman ve Esra Kasapbaşı tarafından çalışmanın sonuçlarından üretilmiştir. 


\section{Sonuç}

İnsan yaşadığı yere karakterini, kültürünü, değerlerini yansıtarak yaşamına uygun hâle getirir. Kendine özgü unsurlarla farklılaştırdığı mekân, sadece fiziksel bir bütün olmanın ötesinde biçimlenir. Bu duruma en iyi örnek, insana özgü en özel mekânsal bütünlerden biri olan konuttur. Konutun sadece değişen boyutlarda, farklı işlevlere sahip mekânların bir araya gelmesiyle oluştuğunu söylemek yanlış bir yaklaşım olacaktır. Konutu oluşturan mekânların; niteliklerinin, kullanımlarının, boyutlarının ve mekânların birbiriyle ilişkilendirilme biçimlerinin, kullanıcının ve onun ait olduğu toplumun değerleri olarak özetlenebilecek belirleyicilerin etkisiyle şekillendiğini söylemek mümkündür.

Çalışma aracılığıyla Gaziantep 1960-1980 dönemi kent konutlarının mekân kurgusunun siyasi, ekonomik ve sosyal şartlar etkisindeki biçimlenişi izlenmek istenmiştir. Belirlenen 20 yıllık süreçte inşa edilen konutların mekânsal değişimi, mekân dizilimi yöntemi yardımıyla incelenirken; yerel kültür öğelerinin mekân kurgusu oluşumu üzerindeki etkileri de saptanmaya çalışılmıştır. Çalışma sonucunda elde edilen veriler 1şı̆̆ında, Gaziantep kent konutunun gelişiminde bir geçiş süreci olduğu hissedilen 1960-1980 dönemine ait konut mekân kurgusu hakkında somut bilgiler ortaya konulması hedeflenmiştir. Çalışmanın sonuçları iki ayrı on yıllık döneme ait toplam 10 adet konutun analiz edilmesiyle ulaşılan bulgulara dayanmaktadır. Belirtilen dönemler içinde, konut örneklerinin nitelik ve nicelik bakımından çeşitlendirilmesinin sonuçları etkileyebileceği ifade edilmelidir.

Elde edilen sonuçlar; ilk on yıllık dönemde 1960'ların başında inşa edilen, her katta tek daire biçimindeki örneklerin, çoğunlukla kullanıcısının özel talepleri doğrultusunda şekillenmiş, özgün tasarımlar olduğunu işaret etmektedir. Bu örnekler, tasarım ve kullanım bakımından Karaman ve Erman'ın aile apartmanı olarak tarif ettiği konut tipiyle benzeşmektedir ${ }^{27}$. 1970-1980 yılları arasını kapsayan ikinci dönem örneklerinde ise önceki dönem konutlarında görülen özgün karakterden farklı olarak, mekân kurgusunda daha fazla anonimleşmenin ve tipleşmenin oluştuğu düşünülmektedir.

Çalışmanın geçiş diyagramı analizi sonuçları ise Erman tarafından gerçekleştirilen ve Adana'da 1950-1970 yılları arasında inşa edilen konut örneklerinin incelendiği çalışmanın mekân dizilimi analizi sonuçlarıyla paralellik göstermektedir ${ }^{28}$. Sözü edilen çalışmada yemek odası, misafir odası ve giriş holü, bu çalışmada da olduğu gibi rota değiştiren mekânlar olarak saptanmıştır. Çalışma, çok sayıda rota değiştiren mekân oluşumunu, geleneksel plan şemasından modern plan şemasına geçişte yeni kullanım alanlarını şemaya dahil etme gayreti ve yeni mekânsal ilişkileri tanımlanma çabası ile açıklamaktadır. Aktarılan sonucun bu çalışma için de geçerli olduğu söylenebilir.

27 Figen Karaman ve Onur Erman, “Apartman Tipolojisinde Bir Aç1lım: 1950-1960’larda Adana Örneğinde Aile Apartmanları," Kent, Kültür ve Konut, ed. Hülya Turgut Yıldız ve Ahmet Eyüce (İstanbul: Bahçeşehir Üniversitesi Yayınları, 2007), 110.

28 Erman, "Mekânsal Komşuluk Kavramı Üzerinden Mimari Mekânın Analizi,” 171-175. 
Geleneksel yaşam kültürünün mekân kurgusuyla olan ilişkisine bakıldığında, yörenin yaşam kültürünün kurgunun biçimlenişine olan etkisi açık biçimde gözlemlenmiştir. İncelenen 1960-1970 dönemi konutlarının çoğunda benzer şekilde tekrar eden kiler, mutfak ve yemek odası ilişkisi, yemek kültürü yönünden ülkemizin sayılı mutfaklarından birine sahip olan Gaziantep kentinin yöresel özelliklerinin ve sosyal yaşam alışkanlıklarının bir göstergesi olarak yorumlanabilir. Genel olarak geniş aile yaşamının sürdürüldüğü, çok sayıda kullanıcının birlikte yaşadığı dönem konutlarının büyük kısmında mekân kurgusu, yemek kültürünün etkisi, ailecek yemek yeme ritüeline önem verilmesi ve sıcak yemek servisinin uygun şekilde yapılabilmesi amacıyla biçimlenmiş̧ir. Bu ilişkinin 1970-1980 döneminde değişerek devam ettiği belirlenmiştir.

Ulaşılan sonuçlar mekân kurgusundaki değişimi anlamak üzere dikkate alındığında geçiş modellerinin adım derinliğinin ikinci on yıllık dönemde azaldığı, bazı mekânların ve mekânsal ilişkilerin kaybolduğu, azalan adım derinliğine bağlı olarak da mekânların ulaşılabilirliğinin arttığı görülmüştür. Benzer şekilde rota değiştiren mekân sayısıyla birlikte halka sayısında da önceki on yıllık döneme göre azalma olduğu, bu doğrultuda mekânsal ilişkilerin değiştiği tespit edilmiştir. Bu sonuçlar ele alınan iki dönem arasında mekânsal kurgunun değişimini açık bir şekilde ifade etmektedir.

Bu bağlamda Gaziantep kent konutu özelinde;

- 1960-1970 dönemi kent konutu örneklerinin, kendine has mekân kurgusunun yanı sıra, Gaziantep kentinin o dönem içinde bulunduğu şartlar, kullanıcısının yaşam biçimi ve tercihlerini yansıtan nitelikte planlama anlayışına ve prensiplere sahip olduğunu,

- Sonraki süreçte inşa edilen, 1970-1980 dönemi konutlarının, günümüzün tipik apartman konutuna ait mekân kurgusunun öncülü niteliğinde olduğunu söylemek mümkündür.

Sonuçta her ne kadar aynı coğrafyada olsa da değişen dönem koşulları yaşam tarzı ve buna bağlı olarak farklılaşan yaşam kültürünün, konut şemasının değişmesine neden olduğu açıkça görülmektedir. Bu sonuç, konutun kültürel bir unsur ve yaşantının bir yansıması, adeta somutlaşmış hâli olduğunu bir kez daha doğrulamaktadır. Bu bağlamda çalışmayla elde edilen sonuçlar, toplum ve onu oluşturan bireylerin yaşamını etkileyen her değiş̧imin, konut mekânına da yansıdığı düşüncesini desteklemektedir.

Ulaşılan sonuçlar 1şığında, 1960-1980 döneminin özgün karakterini taşıyan Gaziantep kent konutlarının; geleneksel konut kültürü ile günümüz konut kültürü arasında bağ kuran, kentin modernleşme sürecindeki yaşam biçimi ve konut kültürünü yansıtan nitelikte olduğu görülmektedir. 
Hakem Değerlendirmesi: Dış bağımsız.

Çıkar Çatışması: Yazarlar çıkar çatışması bildirmemiştir.

Finansal Destek: Yazarlar bu çalışma için finansal destek almadığını beyan etmiştir

Peer-review: Externally peer-reviewed.

Conflict of Interest: The authors have no conflict of interest to declare.

Grant Support: The authors declared that this study has received no financial support.

\section{Kaynakça/References}

Bafna, Sonit. "A Brief Introduction to Its Logic and Analytical Techniques.” Environment and Behavior 35 (2003): 17-29.

Coşkun, Derya. “Gaziantep’te Konutun Gelişimi.” Erişim 5 Haziran 2020. https://www.arkitera. com/gorus/gaziantepte-konutun-gelisimi/

Dursun, Pelin. "Trabzon Kentsel Dokusunda Morfolojik Analiz.” Doktora tezi, İstanbul Teknik Üniversitesi, 2002.

Erman, Onur, Figen Karaman, Duygu Saban ve İpek Durukan. “Adana’da, 1930’lardan Günümüze, Sosyal, Kültürel ve Ekonomik Değişimler Bağlamında Konut Mimarisinin Gelişimi.” Bilimsel araştırma projesi, Çukurova Üniversitesi BAP Birimi, Proje No: MMF2006BAP5, 2007.

Erman, Onur. "Mekânsal Komşuluk Kavramı Üzerinden Mimari Mekânın Analizi.” Çukurova Üniversitesi Mühendislik Mimarlık Fakültesi Dergisi 32 (2017): 165-176.

Gündoğdu, H. Meltem. "Mekân Dizimi Analizi Yöntemi ve Araştırma Konuları.” Art-Sanat 2 (2014): 251-274. Erişim 7 Temmuz 2019. https://dergipark.org.tr/en/download/article-file/92900.

Güney, İ. Yasemin. “Appropriated 'A la Franga': An Examination of Turkish Modernization Through The Lens of Domestic Culture.” Doktora tezi, University of Michigan, 2005.

Güneyligil, Şahap. "Piyano Kazandıran Ev.” TMMOB Mimarlar Odası Gaziantep Şubesi Mimarlı Bülteni 10 (2007): 6-9.

Gür, Ö. Şengül. Doğu Karadeniz Örneğinde Konut Kültürü. İstanbul: Yem Yayın, 2000.

Hanson, Julienne. Decoding House and Homes. Cambridge: University Press, 1998.

Hillier, Bill ve Julienne Hanson. The Social Logic of Space. Cambridge: Cambridge University Press, 1984.

Hillier, Bill, Julienne Hanson ve Hilliaire Graham. "Ideas are in Things." Environment and Planning B: Planning and Design 14 (1987): 363-385.

Hillier, Bill. Space is The Machine. London: Space Syntax, 2007.

Hillier, Bill. "Space Syntax as a Method and as a Theory." $21^{\text {st }}$ International Seminar on Urban Form, ISUF2014, 3-6 Temmuz 2014 Portekiz. Erişim 21 Haziran 2019. http://isuf2014.fe.up. pt/Hillier.pdf

İller Bankas1, İmar Planlama Dairesi Reisliği. Gaziantep Kent Bütünü Analitik Etüdleri. Ankara: Ofset Fotomekanik Matbaas1, 1972.

İller Bankası, İmar Planlama Dairesi Başkanlığı. Gaziantep Tatbikat İmar Planı, 1978.

Karaman, Figen ve Onur Erman. “Apartman Tipolojisinde Bir Açılım: 1950-1960’larda Adana Örneğinde Aile Apartmanları.” Kent, Kültür ve Konut. Ed. Hülya Turgut Yıldız ve Ahmet Eyüce. İstanbul: Bahçeşehir Üniversitesi Yayınları, 2007, 107-114. 
Köylüoğlu, Akten. Kadim Şehir Gaziantep. Gaziantep: Neşa Ofset, 2009.

Kuyucu, Feyza ve Yasemen Say Özer, “Hermann Jansen'in Planlama İlkelerini Gaziantep Kent Planı Üzerinden Okumak." Mimarlık. 409 (2019): 63-67.

Lefebvre, Henry. Mekânın Üretimi. Çev. Işık Ergüden. İstanbul: Sel Yayıncılık, 2014.

Peponis, John, Jean Wineman, Mahbub Rashid, Hong S. Kim ve Sonit Bafna. "On The Description of Shape and Spatial Configuration Inside Buildings: Convex Partitions and Their Local Properties." Environment and Planning B: Planning and Design 24 (1997): 761-781.

Peponis, John ve Jean Wineman. "Spatial Structure of Environment and Behavior." Handbook of Environmental Psychology. Ed. Robert B. Bechtel ve Azra Churchman. New York: John Wiley \& Sons, 2002, 271-291.

Tatlıgil, Feyza. "Gaziantep Kentinin Geleneksel Konut Dokusunun ve Sosyokültürel Yapısındaki Değişimin İncelenmesi.” Yüksek Lisans Tezi, Yıldız Teknik Üniversitesi, 2005.

Vidler, Athony. Warped Space, Art, Architecture, and Anxiety in Modern Culture. Cambridge: The MIT Press, 2000.

Yenice, M. Serhat ve Tülay Karadayı Yenice. "Gaziantep Kenti Planlama Deneyimleri Üzerine Bir Süreç Değerlendirmesi.” Gaziantep University Journal of Social Sciences 17 (2018): 552-562.

Yetkin, Hulusi. Gaziantep Tarihi ve Davaları. Gaziantep: Yeni Matbaa, 1968.

depthmapX. https://www.ucl.ac.uk/bartlett/architecture/research/space-syntax/depthmapx. Erişim 12 Ağustos 2019.

Google_Haritalar._https:/www.google.com.tr/maps/place/Gaziantep/@37.0596092,37.3575988,14 $57 \mathrm{~m} /$ data $=$ !3m1!1e3!4m5!3m4!1s0x1531e6b4f7f18c2f:0xc02e8b35116baad0!8m2!3d37.06595 3!4d37.37811. Erişim 20 Mayıs 2019 
